\title{
UN ANÁLISIS DEL PROBLEMA ÉTICO Y LEGAL DEL TRATAMIENTO DEL CÁNCER CERVICOUTERINO EN MUJERES EMBARAZADAS
}

\author{
Alejandra Urra P. ${ }^{a}$, Mikel Urquiza R. ${ }^{a}$, Ricardo Mewes A. ${ }^{a}$, Marcelo González V. ${ }^{1}$, \\ Juan Pablo Beca I. ${ }^{2}$ \\ 1 Departamento de Obstetricia y Ginecología, Clínica Alemana. ${ }^{2}$ Centro de Bioética, Facultad de Medicina, Clínica \\ Alemana, Universidad del Desarrollo.
}

a Alumnos de Medicina, Facultad de Medicina, Clínica Alemana, Universidad del Desarrollo.

\section{RESUMEN}

Se analiza el problema ético y jurídico del tratamiento del cáncer cervicouterino en mujeres embarazadas. Se realizó una revisión del tema, de las leyes chilenas y de algunas normativas europeas para después analizar la aplicación de los principios de No Maleficencia, Beneficencia, Autonomía y del Doble Efecto. El tema genera una difícil discusión e interpretación, pues tanto las leyes como los principios son orientadores, pero no explícitos para decidir la conducta más adecuada en cada caso. Lo ideal es preservar la vida materna y fetal, pero hay casos en los que, finalmente, es necesario priorizar una sobre la otra. Corresponde al equipo tratante, la madre, el padre, la familia y la sociedad concordar las conductas más responsables y justas posibles.

PALABRAS CLAVE: Cáncer cervicouterino, embarazo, jurisdicción chilena, aborto terapéutico, ética

\section{SUMMARY}

Authors analyze the ethical and legal problem about the treatment of cervical cancer in pregnant women. A review of the Chilean laws and European regulations was made in order to analyze the application of the principles of Non maleficence, Beneficence, Autonomy and the Double Effect. The subject generates a difficult discussion and interpretation since both, law and principles, are guiding but do not give an explicit answer to choose the more appropriate behavior in each case. The goal is to preserve maternal and fetal life, but there are cases in which it is necessary to prioritize one over the other. A consensus between medical staff, the mother, the father, the family and society is necessary for a more responsible and fair decision.

\section{KEY WORDS: Cervical cancer, pregnancy, chilean jurisdiction, therapeutic abortion, ethic}

\section{INTRODUCCIÓN}

El cáncer cervicouterino $(\mathrm{CaCu})$ es la neoplasia maligna ginecológica que se diagnostica con mayor frecuencia en el mundo, con 500.000 casos nuevos y 280.000 muertes cada año de las cuales aproximadamente el $80 \%$ ocurre en países en desarrollo (1). En Chile este cáncer representa la segunda causa de muerte después de las enfermedades cardiovasculares (2), siendo el $\mathrm{CaCu}$, el quinto más frecuente en mujeres (3). La mortalidad por este cáncer se presenta mayoritariamente en el grupo de mujeres entre 25 y 64 años $(61,6 \%)$ seguido del grupo mayor de 64 años $(38,2 \%)$. 
Analizando el subgrupo de mujeres de edad fértil entre 15 y 54 años se encontró una predominancia de la mortalidad en el subgrupo de 50 a 54 años $(10,3 \%)$ seguido en segundo lugar por el subgrupo entre 45 y 49 años $(10,2 \%)$ y en tercer lugar se encuentra el subgrupo entre 40 y 44 años $(8,8 \%)$. En todos los grupos etarios existe una tendencia descendente y significativa de la mortalidad, con excepción del rango de mujeres entre 20 y 24 años (2). En Europa y Norteamérica, su incidencia y mortalidad han disminuido en las últimas décadas, debido a la detección precoz de lesiones preinvasoras en mujeres asintomáticas usando la técnica de citología exfoliativa (Papanicolaou). El tamizaje realizado con pruebas más sensibles para detectar lesiones en el cuello uterino usando PCR y captura híbrida, son conocidos como el "Human Papiloma Virus Test" (HPV TEST) el cual logra una sensibilidad de $99 \%(4,5)$. Sin embargo, de acuerdo a los datos de la Organización Mundial de la Salud (OMS), las tasas de mortalidad por $\mathrm{CaCu}$ son mucho mayores en países en desarrollo (6).

Una situación particularmente difícil se presenta en mujeres que presentan un $\mathrm{CaCu}$ en el curso de un embarazo. Surge así la interrogante de qué sucede con el cáncer, dado que el feto se encuentra en el mismo órgano donde progresa la neoplasia (7). Se presentan difíciles preguntas en relación con qué alternativa de tratamiento elegir ante el conflicto de valores entre la vida fetal y la salud de la madre. Desde el punto de vista bioético los problemas son cómo respetar, en esta situación particular, el principio de No Maleficencia en juego en el daño al feto, y cómo respetar el principio de Autonomía en el derecho a decidir de la paciente. El propósito de este artículo es analizar los aspectos éticos y jurídicos del problema que se presenta en mujeres en quienes se diagnostica un $\mathrm{CaCu}$ durante el embarazo.

\section{HECHOS CLÍNICOS}

El CaCu es la neoplasia diagnosticada con mayor frecuencia durante el embarazo y cerca del $3 \%$ de los casos de primer diagnóstico de $\mathrm{CaCu}$ se realiza en mujeres embarazadas (8). De todas las mujeres con $\mathrm{CaCu}$ un $0,8 \%$ de ellas están embarazadas. Algunos estudios indican que el embarazo no afecta el pronóstico del cáncer en comparación con el de la población no gestante $(9,10)$. En Chile el tratamiento se realiza siguiendo un protocolo del Ministerio de Salud según la etapificación del cáncer $(1,11)$.

En la mujer gestante es necesario adoptar un criterio personalizado una vez que se decide iniciar tratamiento del cáncer, teniendo presente que la radioterapia provocará malformación o muerte fetal (12-13). Hay que tener presente que el cisplatino ha demostrado no tener efectos sobre el desarrollo fetal en el embarazo (14). Para el tratamiento se sugiere considerar el estadio clínico del cáncer, la edad gestacional en el momento del diagnóstico y las preferencias de la paciente y las de su familia (15). En el estadio IA1 en el cual existe microinvasión se realiza conización en pacientes jóvenes como tratamiento de excepción, con fin de preservar la fertilidad y permitir la realización de sus expectativas de maternidad. Para estadios más avanzados se diferencian las opciones de tratamiento dependiendo del estadio y la edad gestacional $(16,17)$.

En aquellos casos de cáncer invasivo en estadio IA1, A2 o B1, diagnosticado antes de las 12 semanas de edad gestacional, se recomienda la realización de tratamiento inmediato y definitivo con el sacrificio del feto derivado de la histerectomía o radioterapia. En aquellos casos más avanzados, estadio IB2 y II, la indicación es comenzar con quimioterapia en base a cisplatino para luego dar paso a la radioterapia y finalmente histerectomía. El estadio III y IVA, no son sometidos a cirugía y se mantienen en otras modalidades de radioterapia. Finalmente el estadio IVB es tratado de manera paliativa. Actualmente no se recomienda retrasar para después del primer trimestre de gestación la quimioterapia, dado el riesgo de progresión y metástasis (17).

El manejo del cáncer cervicouterino después del primer trimestre y con el feto no viable se recomienda el tratamiento inmediato y definitivo en aquellas mujeres con tumores de células escamosas poco diferenciados, localmente avanzados o con adenocarcimonas, así como todas las que demuestren progresión de la enfermedad durante el embarazo. Las opciones de tratamiento en etapas IA, IB y IIA antes de las 20 semanas de gestación son la histerectomía radical con el feto in situ o terapia de radiación, lo cual implica interrumpir el embarazo (17). Luego de las 20 semanas de gestación se evacúa al feto antes de la histerectomía y linfadenectomía, produciéndose su muerte indeseada a causa de su inviabilidad (18). El retraso del tratamiento con estrecha vigilancia para alcanzar la madurez pulmonar fetal puede ser planteado en aquellos casos que se detecta después de las 20 semanas. En casos seleccionados el retraso del tratamiento puede ser complementado con la administración de quimioterapia neoadyuvante en carcinomas localmente avanzados en un esfuerzo por permitir llegar a la viabilidad fetal (18). Sin embargo, los quimioterápicos no son inocuos, actualmente hay evidencia de que se puede utilizar el cisplatino durante el segundo y tercer trimestre, pero aún no 
existe información suficiente como para asegurar que es un fármaco seguro (19). El grado en que el feto es afectado depende de la droga de elección que se ocupe, su momento de aplicación, duración, dosis y farmacocinética de la droga. En cuanto a la exposición del feto a la quimioterapia, lo predispone a tener un retardo del crecimiento intrauterino, prematuridad, bajo peso al nacer, riesgo de malformaciones fetales y supresión hematopoyética (17).

Por último, en el caso de $\mathrm{CaCu}$ invasivo con un feto viable o una vez alcanzada la madurez fetal, se recomienda realizar parto por cesárea inmediatamente. Esta debe ser seguida de una histerectomía radical y radiación de toda la cavidad pélvica en caso de etapas avanzadas (17).

El pronóstico en caso del cáncer invasivo no tiene diferencias cuando se hace la comparación entre la población embarazada y la no embarazada. En casos de la etapa I del $\mathrm{CaCu}$ el retraso del tratamiento parece ser seguro, no así en las siguientes etapas donde aumenta la invasión del cáncer a las estructuras vecinas y posibles metástasis (17).

\section{MARCO LEGAL}

Las normativas legales en muchos países establecen condiciones y procedimientos para aceptar legalmente el "aborto terapéutico" (20). La mayoría se rige por las siguientes consideraciones, bajo las cuales un aborto se consideraría terapéutico: 1) que la vida materna estuviera en peligro, 2) para preservar la integridad física y mental de la mujer, y 3) para disminuir el riesgo de los embarazos múltiples mediante la reducción selectiva del número de fetos. En base a estos criterios cada país tiene diferentes procedimientos para implementar la decisión, como ocurre en Inglaterra donde es necesaria la aprobación de dos médicos que evalúen independientemente la necesidad del aborto (20).

En Chile no existe ninguna de estas normativas específicas y sólo hay consideraciones generales como las de la Constitución Política que establece en su Artículo 19: "La Constitución asegura a todas las personas: 1 El derecho a la vida así como a la integridad física y psíquica de la persona" (21). Por otra parte el Código Civil establece en el Artículo 75: "La ley protege la vida del que está por nacer". El juez, en consecuencia, tomará a petición de cualquier persona todas las providencias que le parezcan convenientes para proteger la existencia del no nacido, siempre que crea que de algún modo peligra. Todo castigo de la madre, por el cual pudiera peligrar la vida o la salud de la criatura que tiene en su seno, deberá diferirse hasta después del nacimiento" (22). El Código sanitario en su Artículo
119 expresa "No podrá ejecutarse ninguna acción cuyo fin sea provocar un aborto" (23). Finalmente el Código Penal deja en claro la ilegalidad del aborto sin hacer distinción alguna sobre las circunstancias, sancionando tanto a la madre como al profesional que lo lleve a cabo señalando en el Artículo 342: "El que maliciosamente causare un aborto será castigado" (24).

\section{DISCUSIÓN}

El CaCu invasivo durante el primer y segundo trimestre del embarazo plantea un problema ético de muy difícil solución, una disyuntiva ante la cual se necesita optar entre el tratamiento radical en la madre con la consecuente muerte fetal, o en el retraso del tratamiento con la probable progresión del cáncer. En caso de tratarse de etapas avanzadas puede llegar a metástasis con la posterior muerte materna dependiendo del grado de invasión. La alternativa podría ser el tratamiento parcial en la madre con quimioterapia esperando la viabilidad fetal, la cual no está exenta de consecuencias para el feto como se mencionó anteriormente. Además del conflicto de valores entre dos vidas, es evidente que la madre puede expresar su voluntad pero no así el feto. Los cuestionamientos que se plantean en esta situación comprometen de diferentes maneras a la sociedad, la legislación, al médico y equipo tratante, la mujer embarazada y su familia, y a quien pudiese representar los intereses del no nacido.

La ley chilena explicita las penas a aplicar a toda persona que interrumpa un embarazo con acciones directas contra el feto, pero no queda claro qué sucede en los casos en los cuales el aborto constituye un efecto indirecto no deseado de un procedimiento médico. El Artículo 19 de la constitución refleja los acuerdos de la Convención Americana Sobre Derechos Humanos, que en su Artículo $4^{\circ}$ se refiere al derecho a la vida. Las garantías que establece no especifican cual es la prioridad y los códigos tampoco son lo suficientemente claros en establecer cuáles son los criterios a seguir cuando se hace necesario priorizar una vida sobre otra. $\mathrm{Si}$ bien no corresponde a la Constitución tratar estas materias de manera específica, en ella se basan las leyes de una nación, por lo que es fundamental que exista una interpretación clara y con bases científicas que dirijan y protejan este tipo de decisiones. Por otra parte, la elección libre que haga la mujer embarazada, con su familia y los profesionales a cargo, debería ser respetada y protegida por la ley. Cabe mencionar la postura jurídica que señala que para permitir el aborto terapéutico no es necesario modificar la ley sino considerar que el médico que 
realice una acción destinada a proteger la salud y la vida de la madre, aunque implique la muerte no buscada del feto, no atenta contra la vida fetal, sino que realiza una acción sanadora conforme a la Lex Artis $(25,26)$.

Desde el punto de vista bioético, hay valores morales y principios éticos que se comprometen al tratar el $\mathrm{CaCu}$ en una mujer embarazada, con cirugía radical y radioterapia, produciéndose secundaria e inevitablemente el óbito del embrión o feto. Es evidente que la salud física y psíquica de la paciente será afectada dependiendo del curso de acción que se asuma. En la decisión terapéutica se comprometen valores como los de responsabilidad y lealtad médica, autonomía de la paciente y respeto por la nueva vida, entre otros. Pero en lo más sustancial se trata de un conflicto de valores entre otorgar el tratamiento más efectivo a la enferma y respetar el derecho a la vida del feto. El análisis desde el principialismo obliga a definir qué decisiones pueden respetar mejor los principios de No Maleficencia, Beneficencia y Autonomía.

Hay dos premisas de referencia moral que se deben considerar: la ontológica y la ética. La primera señala que "el hombre es persona y en cuanto tal tiene dignidad y no precio", y la segunda afirma que "en cuanto a las personas, todos los hombres son iguales y merecen igual consideración y respeto" (27). El dilema es considerar si una de estas vidas tiene mayor valor $\mathrm{o}$, en otras palabras, a cuál se debería privilegiar. Las teorías acerca del inicio de la vida humana son complejas, y su aplicación es difícil en relación a las conductas con el feto que es un ser humano aún no nacido. Si se piensa desde el concepto de la dignidad intrínseca de la vida humana desde su inicio, se debería concluir que el feto se debe tratar con la misma consideración y respeto que a un ser humano ya nacido. Algunos estiman que el embrión debe ser siempre respetado y protegido de manera absoluta, mientras que otros consideran que su estatuto o valoración moral es gradual y progresivo a lo largo del periodo preimplantacional o aún hasta semanas después de implantado (28). Este concepto considera el "proceso epigenético" en el cual, en parte por medio del intercambio con el medio materno y luego con el ambiente, durante la vida intrauterina y después de nacer, se definirá su fenotipo final constituyendo su identidad definitiva (29). Si se considera esta visión, no se estaría afectando a una persona humana sino a una vida aún no plenamente constituida, por lo cual nuestra obligación con ella sería menor que nuestro deber de tratar a la madre.

La obligación de respeto al principio bioético de No Maleficencia, considerado como un principio de primer nivel, obliga a proteger la vida del no nacido si se le considera persona humana. Sin embargo, este deber necesita ser aplicado en armonía con la obligación moral de tratar una enfermedad de alto riesgo vital para la madre, lo cual es una acción que respeta el principio de Beneficencia.

El derecho a decidir de los padres es indiscutible ante decisiones respecto a ellos mismos y a su salud. También tienen derecho a representar los intereses de sus hijos desde el inicio, por ser ellos los primeros responsables del destino de los embriones y del cuidado de sus futuros hijos. De acuerdo con lo anterior, respetando así el principio de Autonomía, son ellos quienes en primer lugar deberían decidir la conducta a seguir. Puede existir también la posibilidad de que el padre y la madre representen intereses distintos o contradictorios entre sí, lo cual plantea la interrogante sobre el derecho del padre en esta situación. En todo caso es importante considerar que los padres no son dueños absolutos de la vida de sus hijos sino los responsables de su cuidado. Por lo tanto, además de los padres, la sociedad tiene la obligación de proteger la vida humana, especialmente la de los más débiles y desprotegidos, concepto que es afirmado también por la Constitución.

En la situación en análisis es muy atingente la discusión del "Principio del doble efecto" que se define como un principio de razonamiento práctico que sirve para determinar la licitud o ilicitud de una acción que produce o puede producir dos efectos, de los cuales uno es moralmente bueno y el otro es malo (30). En otros países se justifica como, terapia de elección la histerectomía, aplicando esta doctrina: buscar la curación del cáncer y aceptar la muerte embrionaria como efecto no buscado, aunque predecible. En otras palabras es aceptar el "mal menor". Esta teoría se defiende porque hay dos efectos: la curación de la mujer con cáncer cervicouterino y la muerte inevitable del embrión o feto, ambos causados por la histerectomía. La posibilidad de curación no se busca como efecto de la muerte del feto sino de la histerectomía, como parte necesaria del tratamiento. Un caso homologable es el de la resección tubaria del embarazo ectópico, situación que no es considerada un aborto.

Algunos filósofos señalan que el mal no tiene entidad propia, porque sólo es ausencia de bien, y el "mal menor" sería sólo carencia de bien (31). Esta doctrina exige procurar siempre el mayor bien posible y, en lo posible, evitar el mal. Esto se plantea en casos en que haya que optar por una conducta en desmedro de otra. En el caso de una neoplasia en estadio avanzado del embarazo, salvaguardar la vida materna realizando el tratamiento indicado, 
aceptando la consecuencia de óbito fetal, sería una aceptación moral del mal menor.

Desde la "ética de la responsabilidad" se señala que el hombre, como ser racional debe hacerse responsable de las consecuencias de sus acciones (32). La responsabilidad exige confrontar los medios con los fines. No todos los medios son lícitos, aunque se tenga la convicción de la conveniencia del fin. Pero es necesario reflexionar acerca de cuál es el fin "correcto" y luego pensar si los medios con sus efectos indeseados son adecuados o no, pues para cada acción, se debe actuar con la responsabilidad que el caso particular amerite.

\section{CONCLUSIÓN}

El CaCu durante el embarazo genera un difícil problema con múltiples interpretaciones, tanto en lo legal como en lo ético. La ley debe respetarse como una obligación moral mínima, pero se debe considerar que ésta siempre tiene que ser interpretada, más aún si la legislación chilena no hace mención explícita a esta situación concreta. Es necesario considerar que la intención, en caso de intervenir quirúrgicamente a la paciente, no es provocar un daño sino buscar el beneficio del tratamiento. En cuanto a los aspectos éticos, en base a las doctrinas del doble efecto, del mal menor, y las visiones sobre el inicio de la vida, es posible fundamentar la idea de priorizar, en algunos casos, la sobrevida de la madre mediante un tratamiento responsable y eficaz. Debe considerarse que, de ser posible, ambas vidas se resguardarían. Finalmente, corresponde al equipo tratante, la madre, el padre y la sociedad, concordar las conductas más responsables y justas posibles.

AGRADECIMIENTOS. Los autores agradecen a la Dra Sofía Salas por su valiosa revisión del manuscrito.

\section{BIBLIOGRAFÍA}

1. Serman F. Cáncer cervicouterino: epidemiologia, historia natural y rol del virus papiloma humano: perspectivas en prevención y tratamiento. Rev Chil Obstet Ginecol 2002;67:318-23.

2. Donoso E, Cuello M, Villarroel L. Reducción de la mortalidad por cáncer cérvico uterino en Chile. Rev Chil Obstet Ginecol 2006;71:307-12.

3. Donoso E, Cuello M. Mortalidad por cáncer en la mujer chilena. Análisis comparativo entre los años 1997 y 2003. Rev Chil Obstet Ginecol 2006;71:10-6.

4. Schiffman $M$, Herrero R, Hildesheim A, Sherman $M$, Bratti M, Wacholder S, et al. HPV DNA Testing in Cer- vical Cancer Screening. JAMA 2000;283:87- 93.

5. Franco EL, Duarte-Franco E, Ferenczy A. Cervical cancer: epidemiology, prevention and the role of human papillomavirus infection. CMAJ 2001;164:1017-25.

6. Organización Mundial de la Salud. Control integral del cáncer cervicouterino. 2007. Disponible en: http:// www.ncbi.nlm.nih.gov/pubmed/11314432?itool=Entr ezSystem2.PEntrez.Pubmed.Pubmed_ResultsPanel. Pubmed_RVDocSum\&ordinalpos $=1$ [fecha de consulta: 02 de octubre de 2009].

7. Patni S, Wagstaff J, Tofazzal N, Bonduelle M, Moselhi $\mathrm{M}$, Kevelighan $\mathrm{E}$, et al. Metastatic unknown primary tumour presenting in pregnancy: a rarity posing an ethical dilema. J Med Ethics 2007;33:442-3.

8. McIntyre-Seltman K, Lesnock JL. Cervical cancer screening in pregnancy. Obstet Gynecol Clin North Am 2008;34:645-8.

9. Zemlickis D, Lishner A, Degendorfer P, Panzarella T, Sutcliffe SB, Koren G. Maternal and fetal outcome after invasive cervical cancer in pregnancy. J Clin Oncol 1991;9:1956-61.

10. Hacker NF, Berek JS, Lagasse LD, Charles EH, Savage EW, Moore JG. Carcinoma of the cervix associated with pregnancy. Obstet Ginecol 1982;59:735-46.

11. Gobierno de Chile Ministerio de Salud. Diagnóstico y tratamiento cáncer cervicouterino. Disponible en: http://ncd.bvsalud.org/lildbi/docsonline/4/5/054-Chile_ Cacu.pdf [fecha de consulta: 18 de octubre de 2010].

12. Nazzal O. Cancer cérvico-uterino y embarazo. Rev Chil Obstet Ginecol 2002;67:34-9.

13. Sood AK, Sorosky JI, Mayr N, Krogman S, Anderson $\mathrm{B}$, Buller RE, et al. Radiotherapeutic management of cervical carcinoma that complicates pregnancy. Cancer 1997;80:1073-8.

14. Tewari K, Cappuccini F, Gambino A, Kohler MF, Pecorelli S, Disaia PJ. Neoadjuvant chemotherapy in the treatment of locally advanced cervical carcinoma management of cervical carcinoma in pregnancy including planned delay of therapy. Cancer 1998;82:1529-34.

15. Takushi M, Moromizato H, Sakumoto K, Kanazawa K. Management of invasive carcinoma of the uterine cervix associated with pregnancy: outcome of intentional delay in treatment. Gynecol Oncol 2002;87:185-9.

16. Alon BA, Levy R, Lavie O, Edwards C, Kaplan A. Conservative treatment of stage IA2 squamous cell carcinoma of the cervix during pregnancy. Obstet Gynecol 2004;104:1129-31.

17. Van Calsteren K, Vergote I, Amant F. Cervical neoplasia during pregnancy: Diagnosis, management and prognosis. Best Pract Res Clin Obstet Gynaecol 2005;19:611-30.

18. Goncalves C, Duarte G, Dias da Costa J, Marcolin A, Bianchi M, Dias D, et al. Diagnosis and treatment of cervical cáncer during pregnancy. Sao Paulo Med J 1009; 127: 359 - 365

19. Mir O, Berveiller P, Ropert A, Goffinet F, Goldwasser. 
Use of platinum derivatives during pregnancy. Cancer 2008;113:3069-74.

20. International Planned Parenthood Federation. Abortion legislation in Europe. Europan Network, 2007. Disponible en: http://www.ippf.org/en/Resources/Reports-reviews/Abortion+Legislation+in+Europe.htm. [fecha de consulta: 15 de octubre de 2009].

21. Constitución Política de la República de Chile. Disponible en: http://www.bcn.cl/lc/cpolitica/index_html. [fecha de consulta: 08 de noviembre de 2009].

22. Código Civil. Disponible en: http://www.leychile.cl/ navegar?idnorma $=172986$. [fecha de consulta: 10 de noviembre de 2009].

23. Código Sanitario. Disponible en: http://www.leychile. $\mathrm{cl} /$ navegar?idnorma $=5595$. [fecha de consulta: $10 \mathrm{de}$ noviembre de 2009].

24. Código Penal. Disponible en: http://www.leychile.cl/ navegar?idnorma=1984. [fecha de consulta: 10 de noviembre de 2009].

25. Tribunal Constitucional. Disponible en: http://www.leychile.cl/navegar?idnorma=270676\&buscar=lex+artis. [fecha de consulta: 22 de Diciembre de 2009].
26. Hermosilla JP, Van Weezel A. Contrapunto: El Aborto Terapéutico. Rev Chil Derecho 2009;36:205-8.

27. Cortina A. Voluntad del entendimiento. En: Cortina A (ed). LA ÉTICA DE LA SOCIEDAD CIVIL. 4aㅡ ed. Madrid: Editorial Grupo Araya, 2002;101-20.

28. Bedate A. El valor ontológico del embrión humano: una visión alternativa. En: Beca JP (ed). EL EMBRION HUMANO. Santiago: Editorial Mediterráneo, 2002;51-544.

29. Kaminker P. Epigenética, ciencia de la adaptación biológica heredable. Arch Argent Pediatr 2007; 105:325-75.

30. Montecinos A. El principio del doble efecto y su relevancia en el razonamiento jurídico. Rev Chil Derecho 2008;35:485-519.

31. Garisoain F. Doctrina y táctica del mal menor. Revista Arbil 112, 2006. Disponible en: http://www.arbil. org/112meno.htm. [fecha de consulta: 10 de Diciembre de 2009].

32. De Siquiera JE. El Principio de Responsabilidad de Hans Jonas. Acta Bioeth 2001;7:371-2. 